\title{
DERECHOS HUMANOS Y EL MECANISMO HÍBRIDO DEL MERCOSUR: ¿CÓMO CONTROLAR LA APLICACIÓN DE LA CLÁUSULA DEMOCRÁTICA?
}

\section{DIREITOS HUMANOS E O MECANISMO HÎBRIDO DO MERCOSUL: COMO CONTROLAR A APLICAÇÃO DA CLÁUSULA DEMOCRÁTICA?}

André de Carvalho Ramos

Resumen: El artículo estudia la forma y la intensidad de la incidencia de los derechos humanos en el proceso de integración del MERCOSUR, con especial atención a los criterios de admisión y permanencia de los miembros en el bloque, una vez que la protección, promoción y garantía de los derechos humanos son condiciones esenciales para la vigencia $y$ evolución del proceso de integración.

Resumo: $O$ artigo estuda a forma e a intensidade da incidência dos direitos humanos no processo de integração do MERCOSUL, com especial atenção aos critérios de admissão e de permanência dos membros no bloco, uma vez que a proteção, a promoção e a garantia dos direitos humanos são condições essenciais para a vigência e para a evolução do processo de integração.

Palabras clave: Derechos Humanos, Derecho de la Integración, MERCOSUR, Solución de diferencias, Protocolo de Ushuaia

Palavras-chave: Direitos Humanos, Direito da Integração, MERCOSUL, Solução de controvérsias, Protocolo de Ushuaia

\footnotetext{
* Profesor de Derecho Internacional y Derechos Humanos dela Facultad de Derecho dela Universidad de São Paulo, Largo São Francisco. Doctor y Profesor Asociado de Derecho Internacional, USP. Visiting Fellow en el Lauterpacht Centre of International Law, Cambridge. Miembro de la Asociación Americana de Derecho Internacional Privado (ASADIP). Miembro de la Sociedad Brasileña de Derecho Internacional. Miembro de la sucursal brasileña de la International Law Association. Miembro del Grupo Ejecutivo del Departamento de Cooperación Jurídica Internacional del Ministerio Público de la Federación. Fiscal Regional de la República. Fiscalía Regional Electoral del Estado de São Paulo (2012-2016). E-mail: andredecarvalhoramos@gmail.com
} 


\section{INTRODUCCIÓN: DE QUÉ HABLAMOS CUANDO HABLAMOS DE LOS DERECHOS HUMANOS EN EL MERCOSUR}

Los derechos humanos consisten en un conjunto mínimo de derechos necesarios para asegurar a los seres humanos una vida fundada en la libertad, la igualdad y la dignidad. Tales derechos se han insertado en las Constituciones (norma interna suprema) o en los tratados internacionales (componiendo las obligaciones internacionales que deben cumplirse por los Estados), siendo reconocidos como parte del núcleo esencial normas del ordenamiento jurídico contemporáneo ${ }^{1}$. Dada la importancia de los derechos humanos para el Derecho Nacional y el Derecho Internacional, es importante estudiar la interacción entre la construcción de un mercado común (como existe en la Europa de hoy, o como lo objetivado, el Mercado Común del Sur - MERCOSUR) y la protección derechos humanos.

El estudio de los derechos humanos en el Mercado Común del Sur (MERCOSUR) es multifacético y puede abordar diversos temas y prismas. Así que, inicialmente, se propone restringir la propuesta del artículo respondiendo a una simple pregunta: de qué hablamos cuando hablamos de "derechos humanos" en el MERCOSUR?".

Primeramente, están los estudios de los derechos humanos en el MERCOSUR en sentido amplio o impropio, en los cuales se analizan las dimensiones de la protección de los derechos humanos en cada uno de los ordenamientos jurídicos internos de los cinco países componentes del bloque. En ese caso, no se utiliza la nomenclatura "MERCOSUR" en el sentido propio del Derecho Internacional, sino como un sinónimo del grupo de países que lo componen.

A su vez, están también los estudios de los derechos humanos en el MERCOSUR en el sentido estricto o proprio, en los cuales se analiza la invocación de los derechos humanos en el Derecho de la Integración del MERCOSUR.

En este segundo tipo de estudio, de carácter claramente internacionalista (a diferencia del primer tipo, de sabor constitucional o nacionalista), hay varias facetas que pueden ser enfocadas, a saber: (i) el estudio de la utilización de los derechos humanos como verdadero filtro de selección y mantenimiento de los países miembros del bloque; (ii) el estudio de las normas de integración que tratan específicamente de los derechos humanos para lograr los objetivos del bloque (en el caso

\footnotetext{
1 Ver extenso estudio sobre el jus cogens y los derechos humanos en RAMOS, André de Carvalho. Teoria Geral dos Direitos Humanos na Ordem Internacional. $5^{\text {a }}$ ed. São Paulo: Saraiva, 2015, p. 184-202.

2 Parafraseando Pedro Cruz Villalón, al referirse a las normas de derechos fundamentales (¿De qué estamos hablando cuando hablamos de derechos fundamentales?). VILLALÓN, Pedro Cruz. "Formación y evolución de los derechos fundamentales". Revista Española de Derecho Constitucional. 1989, vol 25, p. 35 y s.
} 
del MERCOSUR, el mercado común); (iii) el estudio de la utilización de los derechos humanos para profundizar la integración, con el uso de la gramática de los derechos para dar formato a los actos integracionistas, para prever actos futuros y para componer los órganos internos, con el objetivo de reforzar la legitimidad democrática y social del bloque; y (iv) el estudio de la utilización de los derechos humanos para combatir los actos integracionistas, evitando que, en el deseo de eliminar las barreras, los derechos sean violados.

Este artículo tiene como objetivo estudiar los derechos humanos en el MERCOSUR en el sentido estricto o propio, abordando el inicio de la discusión de los derechos humanos en una organización internacional de integración, es decir, precisamente, la entrada y el mantenimiento de sus miembros en el bloque ${ }^{3}$. Una integración económica que no tenga en cuenta los derechos humanos no prosperará, sea por reacción interna (de los tribunales constitucionales de los Estados involucrados) o por reacción internacionalista (de los órganos internacionales de protección de los derechos humanos).

El respeto por el Estado de Derecho yla democracia como requisito de entrada y permanencia en el bloque también inculca en los agentes económicos la fiabilidad requerida para que se hagan las operaciones y las inversiones previstas, así como sirve para legitimar el propio proceso de integración a los ojos de cada una de las poblaciones involucradas.

\section{ASPECTOS GENERALES DE MERCOSUR}

Como resultado de intensas negociaciones, se firmó el 26 de marzo de 1991, por Brasil, Argentina, Uruguay y Paraguay, el "Tratado de Asunción para Constitución del Mercado Común del Sur”. Después del depósito de las ratificaciones necesarias, el Tratado de Asunción entró en vigor el 29 de noviembre 1991.

El Tratado de Asunción de 1991 es un hito en el lento proceso de integración entre las economías de los Estados del Cono Sur americano a establecer, como objetivo final, la constitución de un mercado común $n^{4}$ entre Brasil, Argentina, Paraguay y Uruguay, y a partir del 12 de agosto

\footnotetext{
3 Este artigo es fruto, con actualizaciones, de capítulo de tesis presentada en el concurso de libre-docencia en Derecho Internacional defendida por el autor en la Faculdad de Derecho de la Universidad de São Paulo (USP). La íntegra de la tesis fue publicada en RAMOS, André de Carvalho. Direitos Humanos na Integração Econômica. Análise comparativa da proteção de direitos humanos e conflitos jurisdicionais na União Europeia e Mercosul. Rio de Janeiro: Renovar, 2008.

4 Para BAPTISTA, el Tratado de Asunción presenta "características dialécticas": es un elemento de cambio y también un elemento de continuidad. Cambio, porque "indicaba un nuevo cuadro, no solo económico y comercial, mas también político". Continuidad, porque "prolongó los esfuerzos integracionistas de Brasil y Argentina, así como los del continente". Ver BAPTISTA, Luiz Olavo. O Mercosul - suas instituições e ordenamento jurídico. São Paulo: Ltr, 1998, p.35-36.
} 
de 2012, también Venezuela ${ }^{5}$. Adicionalmente, son Estados asociados Bolivia, Chile (a partir de 1996), Perú (a partir de 2003), Colombia, Ecuador (a partir de 2004), Guyana y Surinam (ambos desde 2013).

De acuerdo con el preámbulo del Tratado para el establecimiento del MERCOSUR, los Estados contratantes anhelan la ampliación de las dimensiones actuales de sus mercados nacionales a través de la integración, lo que constituye condición fundamental para acelerar sus procesos de desarrollo económico con justicia social. El ejemplo europeo de integración económica es mencionado, indirectamente, en el preámbulo del Tratado de Asunción, pues los Estados tuvieron en cuenta "la evolución de los acontecimientos internacionales, en especial la consolidación de grandes espacios económicos y la importancia de lograr una adecuada inserción internacional para sus países".

Desde entonces se anhela la libre circulación de bienes, servicios, personas y capital entre los países miembros (las llamadas "cuatro libertades" de un mercado común), así como la adopción de una política comercial común frente a Estados terceros, además de la coordinación y la armonización de las políticas económicas generales y sectoriales. Por lo tanto, los Estados decidieron establecer un mercado común, con libre circulación de "bienes, servicios y factores productivos entre los países" (artículo $2^{\circ}$ del Tratado).

A pesar de recibir influencia del objetivo audaz de la constitución de un mercado común que surge de la experiencia europea, el MERCOSUR es dominado por las características típicas de las organizaciones internacionales intergubernamentales: todas las decisiones se toman por consenso y los órganos de decisión están compuestos por representantes de los Estados 6 . Sin embargo, desde 1991 hubo una institucionalización creciente del MERCOSUR, que cuenta, con una compleja red de organismos propios e incluso un tribunal permanente de revisión?.

5 En 2005, Venezuela presentó pedido de adhesión plena al MERCOSUR, con acogida consensual del pleito por la Decisión CMC no 29/05, de 8 de diciembre de 2005. El Protocolo de adhesión de la República bolivariana de Venezuela al MERCOSUR fue firmado en 2006, pero la adhesión de Venezuela al MERCOSUR fue concluida solamente en 2012 (seis años de espera - ver abajo la crisis del impeachment del Presidente Lugo), por medio de la Decisión del Consejo Mercado Común no 27/12. Como la propia decisión estableció, no hubo la necesidad de incorporación de dicha decisión CMC, por regular aspectos de la organización del bloque. Integra de la decisión disponible en: <http://www.desenvolvimento.gov.br/arquivos/ dwnl_1377717164.pdf>, [último acceso en 24 de junio de 2006].

6 CASELLA defiende que "continuemos, así, en presencia de modelo estrictamente clásico de negociación diplomática intergubernamental, estando colocados elementos de cooperación, sin que se pueda caracterizar la integración, a través del ejercicio de poderes supranacionales". Continua el citado Autor: "La composición y la actuación de los órganos ejecutivos del MERCOSUR tienen configuración estrictamente intergubernamental, con delimitación de áreas de competencia y actuación marcadas por poca flexibilidad". Ver en CASELLA, Paulo Borba. Mercosul: exigências e perspectivas. Integração e Consolidação de espaço econômico. São Paulo: Ltr, 1996, p.159.

7 Para KLOR y ARROYO, la institucionalización del MERCOSUR consiste en un "proceso que dotaría el sistema de órganos permanentes, aptos a actuar de manera autónoma en relación a 
Además de una creciente institucionalización, el MERCOSUR tiene cifras significativas: corresponde a aproximadamente el 71,8\% (12.789.558 kilómetros cuadrados) del territorio de América del Sur, poseyendo tres veces el área de la Unión Europea. La población del MERCOSUR alcanza 275 millones de habitantes y su economía formal tiene un PIB nominal de aproximadamente 3320 mil millones de dólares, ocupando la quinta posición mundial si se considera como un solo Estado ${ }^{8}$.

Es en este contexto de mayor densidad institucional y ampliación del número de Estados (miembros y asociados) es que vale la pena reflexionar sobre el papel de los derechos humanos en el bloque, como veremos a continuación ${ }^{9}$.

\section{EL PAPEL DE LOS DERECHOS HUMANOS EN LA CONSTRUCCIÓN DE UN PROCESO DE INTEGRACIÓN}

Hay controversia sobre el papel que debe desempeñar la protección de los derechos humanos en el proceso de integración económica. En la experiencia de la integración europea han existido momentos de segregacionismo en los cuales la protección de los derechos humanos se consideraba ajena a los objetivos económicos perseguidos por los Estados $^{10}$. En el caso del MERCOSUR, hay aún aquellos que, como Sabóia, entienden que la protección de los derechos humanos en los países miembros debe limitarse a los mecanismos internacionales de derechos humanos específicos, a la vez que "(...) en el MERCOSUR, cuyos miembros y asociados son parte del sistema interamericano, no cabría, en mi opinión, duplicar el marco legal y procesal"11.

Sin embargo, la construcción de un mercado común tal como existe hoy en Europa o como el objetivado por el MERCOSUR pasa, necesariamente, por los debates sobre los derechos humanos. En resumen, la construcción de un mercado común en un proceso de integración

los Estados-Partes DREYZIN DE KLOR, Adriana e ARROYO, Diego P. Fernández. “O Brasil diante da institucionalização e ao Direito do Mercosul”. En: MENEZES, Wagner (ed). $O$ Direito Internacional e o Direito Brasileiro. Homenagem a José Francisco Rezek. Ijuí: Editora Unijuí, 2004. p. 318-353, en particular p.320.

8 Datos disponibles en http://www.mercosul.gov.br/index.php/saiba-mais-sobre-o-mercosul, último acceso en 25 de junio de 2015.

9 RAMOS, André de Carvalho. Teoria Geral dos Direitos Humanos na Ordem Internacional. $5^{\text {a }}$ ed. São Paulo: Saraiva, 2015, en particular p. 38.

10 Véase decisión del Tribunal de Justicia de las Comunidades Europeas de 4 de febrero de 1959, Friedrich Stork et Cie contre Haute Autorité de la CECA, caso 1/58. Recueil 1959, pp.4387. Más en RAMOS, André de Carvalho. Direitos Humanos na Integração Econômica. Rio de Janeiro: Ed. Renovar, 2008.

11 Sin embargo, el embajador brasileño reconoce la ampliación de la agenda del MERCOSUR, que incluye actualmente compromisos de defensa del régimen democrático. SABÓIA, Gilberto Vergne. "União Européia, Mercosul e a proteção dos direitos humanos". En: PIOVESAN, Flávia (ed). Direitos Humanos, Globalização Econômica e Integração Regional. São Paulo: Ed. Max Limonad, 2002. p. 163-170, en particular p. 167. 
económica regional requiere que haya, entre dos o más Estados, la libre circulación de bienes y servicios de capital y de establecimiento, también conocidas como las "cuatro libertades".

Estas libertades económicas tienen, en varias ocasiones, idéntica sustancia a los derechos humanos reconocidos en los diplomas nacionales e internacionales. Por ejemplo, la libertad de establecimiento se confunde con la libertad de locomoción y el libre ejercicio de una profesión.

Al cabo, ¿es posible separar la materia atiniente, a la integración económica de la que se relaciona con la protección de los derechos fundamentales? La respuesta es negativa.

En primer lugar, los derechos humanos constituyen las libertades económicas. Al principio, es fácil demostrar que los derechos económicos ${ }^{12}$ son parte de las libertades económicas. Sólo mencionar el derecho a la propiedad, así como los derechos al trabajo y al ejercicio de una actividad profesional. Además, los derechos civiles y políticos también componen las libertades económicas, pues es evidente que, por ejemplo, el derecho a la igualdad de trato es conditio sine qua non de la libre circulación de los factores de producción. Admitir tratamientos discriminatorios significa impedir que las libertades económicas se concreticen efectivamente.

Así, por ejemplo, es obligación de los Estados combatir las prácticas discriminatorias que afectan a la libre circulación de los factores de producción. Fue lo que decidió el Tribunal de Justicia de las Comunidades Europeas (TJCE) en el caso Brickell, en el que un ciudadano alemán, y otro austríaco exigieran el mismo tratamiento que se da en los procesos penales italianos (o sea, materia distante de las actividades económicas), a los nacionales de origen germánico. En el caso, los italianos de origen germánico en la región del Tirol italiano utilizan el alemán, sin intérpretes, ante la Justicia local, la cual dispone de personal (incluso jueces) conocedor del idioma. El Tribunal de Justicia Europeo dictaminó que tal prerrogativa de utilizar la lengua alemana ante la justicia italiana en el Tirol fuera extendida a todos los ciudadanos de los Estados miembros, pues consideró que tal restricción a residentes en suelo italiano sería violación de la libre circulación de personas. Sin embargo, mientras que se violaba una de las "libertades económicas", se vulneró también el derecho a la igualdad ${ }^{13}$.

12 Los derechos dichos económicos, por su turno, son aquellos relacionados con la organización de la vida económica de un Estado, en la óptica productor-consumidor. Ver más sobre la clasificación de los derechos humanos en derechos civiles, políticos, sociales, económicos y culturales en RAMOS, André de Carvalho. Teoria Geral dos Direitos Humanos na Ordem Internacional. 5a ed. São Paulo: Saraiva, 2015. p. 130-134.

13 Juzgamiento del Tribunal de Justicia de las Comunidades Europeas de 24 de noviembre de 1998, Procédure pénale contre Horst Otto Bickel et Ulrich Franz. Caso C-274/96. Recueil de jurisprudence 1998, p. I-07637 
Este es el aspecto positivo de los derechos humanos en un proceso de integración. La protección de los derechos humanos implica facilitar o incluso concretizar la integración.

En segundo lugar, los derechos humanos sirven para condicionar el diseño normativo de las libertades económicas. Una política común de defensa de la competencia necesaria para la consecución de una auténtica libertad de circulación de bienes y servicios está condicionada, como demuestra el ejemplo europeo, por la necesidad de respetar el derecho de defensa, contradictoria y apelación, es decir, el debido proceso. En uno de los casos célebres del Tribunal de Justicia de la UE, se aceptó la restricción a la libre circulación de revistas que contienen juegos o premios en nombre de la necesidad de preservar la libertad de expresión. En el caso del MERCOSUR, la libre circulación de ciertos bienes (neumáticos usados) sufrió severas críticas precisamente por violar, al parecer, el derecho a un medio ambiente sano ${ }^{14}$.

De todos modos, los derechos humanos poseen, en principio, una dimensión subjetiva que limita el ejercicio del poder y, por lo tanto, afectan a cualquier tipo de acto estatal, incluso los relacionados con la actividad económica. Este es el aspecto negativo de los derechos humanos en un proceso de integración, lo cual no debería, en el deseo de crear un mercado común, violar los derechos conquistados y ya reconocidos a nivel nacional (Constituciones) e internacional (Derecho Internacional de los Derechos Humanos).

En resumen, no es posible elaborar una política integracionista, con el objetivo de crear un mercado común o una unión económica más profunda, sin, al mismo tiempo, influenciar y alcanzar los derechos de los individuos. Hay identidad e interacción recíproca entre el contenido de las libertades económicas y los derechos titulizados por los individuos.

$\mathrm{Al}$ contrario de lo que ocurre en otras áreas del conocimiento jurídico en los cuales hay una aceptación de la fuerza impulsora de los derechos humanos, hubo una reticencia inicial al considerar que el objeto de las normas internacionales de integración económica (la creación de un mercado común, por ejemplo) tenía relación con la protección de los derechos humanos.

Esta ola "negacionista" afecta tanto a los Estados como la doctrina, como muestra la experiencia europea y del MERCOSUR. De hecho, hubo llamativa omisión de los tratados instituidores originarios sea de las Comunidades Europeas, o del MERCOSUR (como veremos más adelante) sobre el tema de la protección de los derechos humanos.

La fuerza expansiva de los derechos humanos fue solemnemente ignorada, quizás por ser temida, ya que ofrece una protección indeseada a los individuos a ser afectados por la integración, o aún por ser

14 Ver estos casos referentes a la Unión Europea y al MERCOSUR en RAMOS, André de Carvalho. Direitos Humanos na Integração Econômica. Rio de Janeiro: Renovar, 2008. 
considerada ajena a un proceso que debería ser esencialmente económico. Sin embargo, hay varios casos concretos de la Unión Europea y también (en menor medida, por la juventud del proceso) del MERCOSUR en los cuales la realidad de la protección de los derechos humanos se impuso ${ }^{15}$.

Por lo tanto, la protección de los derechos humanos es parte esencial de cualquier proyecto de integración económica. Negar esta realidad es una opción política que, lejos de ser pragmática o funcionalista, conspira contra una unión más profunda, pues justamente impide que haya una reacción coordinada contra las violaciones de los derechos humanos, que impiden el flujo libre de factores de producción y que obstaculizan la defensa de la calidad de vida y la dignidad humana en los varios Estados integrantes del proceso.

\section{LOS DERECHOS HUMANOS EN EL MERCOSUR: LA OMISIÓN DE LOS TRATADOS}

El derecho primario del MERCOSUR es compuesto esencialmente por el Tratado de Asunción (1991), el Protocolo de Ouro Preto (1994) y el Protocolo de Olivos (2004). Estos acuerdos son considerados típicamente acuerdos de integración económica, porque tratan del delineamiento básico de la organización internacional integracionista, sus objetivos e instrumentos, así como de su sistema de solución de controversias.

No hay ninguna disposición específica o un capítulo aparte sobre la protección de los derechos humanos en estos tratados. Sin embargo, el Tratado de Asunción dispone, en su preámbulo, varios objetivos relacionados con la calidad de vida de las personas de los países miembros del bloque en formación. En el primer párrafo del preámbulo, se acordó que la ampliación de las dimensiones actuales de los mercados nacionales de los Estados miembros constituye una condición fundamental para acelerar sus procesos de desarrollo económico con justicia social. Adicionalmente, reconocieron los estados que el MERCOSUR debe almejar "mejorar las condiciones de vida de sus habitantes" (sexto párrafo del Preámbulo). En el Protocolo de Ouro Preto (1994), hubo una breve mención, en el preámbulo, a la "necesidad de una consideración especial para los países y regiones menos desarrolladas del MERCOSUR".

Así que, en los preámbulos de los dos principales acuerdos del Derecho del MERCOSUR, hay una mención débil a objetivos sociales, no económicos de la integración. Sin embargo, no hay en los textos de los tratados citados cualquier mención explícita a la protección de los derechos humanos, o a su relación (inexorable) con el proceso de integración. Esta tibieza de los Estados se explica por el diseño

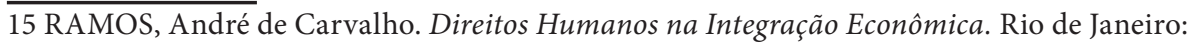
Renovar, 2008. 
minimalista del MERCOSUR, que tiene como objetivo la formación de un mercado común en etapas, siendo que la más factible de ser alcanzada (todavía en formación) es la unión aduanera. En este contexto, no había mayor divagación sobre el impacto de la integración económica en la protección de los derechos humanos.

Por supuesto que no es posible desconsiderar la importancia del texto del preámbulo de un tratado. El preámbulo de un tratado internacional se define como siendo un conjunto de declaraciones sobre las razones de su celebración, sus principios generales y los objetivos primordiales del acuerdo de voluntades. No es de hoy que la doctrina y la jurisprudencia debatan sobre la naturaleza jurídica de los preámbulos. A pesar de la ausencia de obligaciones específicas a los Estados contratantes, el cuerpo del preámbulo de un tratado no es una pieza vacía de contenido y significado: por el contrario, principios y referencias generales mencionadas en los mismos sirven para aclarar el alcance y el sentido de las normas plasmadas en los tratados. De hecho, tal como se establece en el artículo 31.2 de la Convención de Viena sobre el Derecho de los Tratados “(...) 2. Para los efectos de la interpretaci6n de un tratado, el contexto comprenderá, además del texto, incluidos su preámbulo y anexos".

Sin embargo, lamentablemente en el ejemplo europeo de nada sirvió. Suponiendo que la experiencia jurídica de la integración europea es uno de los posibles modelos al MERCOSUR, es evidente que los últimos años de aquel proceso demuestran ser imposible separar, la protección de los derechos humanos y la integración económica regional de un mercado común.

La fuerza expansiva de la integración y también la fuerza expansiva de los derechos humanos resultan en una zona de intersección. El análisis de casos del Tribunal de Justicia de la Unión Europea muestra que los casos típicos de derechos humanos se discutieron en el foro judicial comunitario, como, por ejemplo, el caso Carpenter ${ }^{16}$ (sobre la expulsión de inmigrante) o el caso Kremzov ${ }^{17}$ (sobre decisión en proceso penal). El análisis de los casos de los tribunales constitucionales demuestra las dificultades existentes cuando una norma del Derecho de la Integración viola derechos humanos establecidos en la Constitución o en los tratados celebrados por un Estado.

En comparación, el Tratado de Asunción fue celebrado más de 20 años después del caso Stauder ${ }^{18}$ del Tribunal de Justicia de la Unión

16 Tribunal de Justicia de la Unión Europea, juzgamiento de 11 de julio de 2002, Caso Mary Carpenter vs Secretary of State for the Home Department, cuestión perjudicial formulada por el Immigration Appeal Tribunal.

17 Tribunal de Justicia de la Unión Europea, juzgamiento de 29 de mayo de 1997, Caso Kremzow vs. Áustria, C-299/95, Recueil p.I-2629, en particular párrafos 16 a 19.

18 Tribunal de Justicia de las Comunidades Europeas, sentencia de 12 de noviembre de 1969, Caso Erich Stauder contra Ville d'Ulm - Sozialamt (cuestión perjudicial promovida por el 
Europea, en lo cual fue revertida la tendencia inicial de aquel tribunal de negar la consideración de cuestiones de derechos humanos en los casos a él sometidos. La raison dêtre de dicho cambio jurisprudencial en la Unión Europea fue, como estudié en obra específica ${ }^{19}$, el inminente choque con las jurisdicciones constitucionales, dado el carácter expansivo de los derechos humanos. Además, la mención de la protección de los derechos humanos en el MERCOSUR podría ayudar, como lo hizo en Europa, a reducir las tensiones sobre eventual déficit democrático del proceso de integración y respeto a los derechos de los individuos involucrados.

Por otro lado, el MERCOSUR cuenta, además de los tratados primarios ya enumerados, con tratados sobre diversos temas, que auxilian indirectamente la integración pretendida entre los Estados del bloque. La diferencia entre los tratados de integración económica directa y los tratados de integración indirecta es sutil: esos últimos acuerdos son elaborados en ámbito del MERCOSUR sobre temas diversos, lo que demuestra su importancia para el desarrollo de la integración del Cono Sur en ambos casos, el sistema de solución de controversias es siempre el sistema del MERCOSUR.

En esta clasificación se pueden encontrar varios "Protocolos del MERCOSUR", relativos a la defensa de la competencia ${ }^{20}$, a la cooperación jurídica internacional ${ }^{21}$, a la jurisdicción en los casos de relación de consumo ${ }^{22}$ y como veremos, el Protocolo de Ushuaia, el Protocolo de Asunción y finalmente, el Protocolo de Ushuaia II, todos ellos relacionados con la defensa de la democracia, una faceta esencial en la promoción de los Derechos Humanos.

Por lo tanto, a pesar de la falta de información específica sobre la protección de los derechos humanos en el Tratado de Asunción y el Protocolo de Ouro Preto (columna vertebral del MERCOSUR hasta la fecha) y también la ausencia de un catálogo de derechos como el de la Unión Europea (Carta de los Derechos Fundamentales) hubo una evidente evolución en la determinación de los derechos en el ámbito del MERCOSUR, especialmente en relación con la admisión y permanencia de los Estados en el bloque.

\footnotetext{
Verwaltungsgericht de Stuttgart - Alemania). Recueil XV, Caso 29/69, p. 419.

19 RAMOS, André de Caravalho. Direitos Humanos na Integração Econômica. Rio de Janeiro: Renovar, 2008.

20 Protocolo de Fortaleza sobre Defensa de la Competencia. Decisión 18/96 do Conselho Mercado Comum (CMC)

21 Protocolo de Las Leñas sobre Cooperación Jurídica Internacional en Materia Civil. Decisión $n^{\circ}$ 4/92 del CMC.

22 Protocolo de Santa María sobre Jurisdicción Internacional en Materia de Relaciones de Consumo. Decisión 10/96 del Consejo Mercado Común.
} 


\section{5. ÁMBITO EXTERNO DE ACTUACIÓN DE LOS DERECHOS HUMANOS EN EL MERCOSUR: LA CLÁUSULA DEMOCRÁTICA}

\subsection{Los antecedentes}

La promoción de la democracia tiene sus raíces en los orígenes del MERCOSUR, especialmente después de la redemocratización brasileña y argentina, sucediendo a los regímenes militares en la región. Los liderazgos civiles en ambos países, recién establecidos en el poder después de años de dictaduras militares, percibirían la necesidad de establecer una integración más profunda entre Brasil y Argentina.

Desde el punto de vista político, era urgente la superación de las animosidades (históricas) y de la búsqueda destructiva por la hegemonía en la zona, que había resultado en una serie de divergencias geopolíticas bilaterales, tales como el uso hídrico y energético de la cuenca del río Paraná, así como el desarrollo de centrales nucleares (generando el espectro de la carrera nuclear en el Cono Sur). La integración BrasilArgentina reforzaba el prestigio interno de los nuevos liderazgos civiles, que lograran obtener, en pocos años, lo que parecía inalcanzable: sustituir la desconfianza y el temor por la unidad y la cooperación. El eco del ejemplo franco-alemán, que fue reconocidamente el motor de la integración europea, es evidente: dos países rivales, con pasado de guerras y desacuerdos, se dan cuenta de lo mucho que pueden ganar con una unión más profunda. Por otro lado, el contexto económico internacional de la época (aguda crisis de balanza de pagos, economías en recesión y altas tasas de inflación) dio origen a la conclusión de varios acuerdos bilaterales que sirvieron como una palanca externa para auxiliar al desarrollo interno.

La "Declaración de Iguazú", firmada por los presidentes José Sarney y Raúl Alfonsín el 30 de noviembre de 1985, fue la formalización de este deseo de integración, con éste se establecieron sus metas en diversos ámbitos (económico, financiero y comercial, básicamente). El 20 de julio de 1986, se celebró el "Acta de Integración Brasil-Argentina", consagrando los principios fundamentales del "Programa de Integración y Cooperación Argentina-Brasil” (PICAB) ${ }^{23}$.

En cuanto a la preservación de la democracia, ya en 1992 fue firmada la Declaración Presidencial de Las Leñas (de 27 de junio de 1992), por la cual fue explicíta la voluntad política de los Estados a favor de la plena vigencia de las instituciones democráticas como condición indispensable para la existencia y el desarrollo del MERCOSUR.

Otro paso importante para la introducción formal del

23 ALMEIDA, Paulo Roberto de. O estudo das relações internacionais do Brasil. São Paulo: Unimarco Editorial, 1999, p. 247-248. SEITENFÚS, Ricardo. Manual das Organizações internacionais. 2a ed. Porto Alegre: Livraria do Advogado, 2000, p. 220. 
mantenimiento de la democracia como un requisito de permanencia en el MERCOSUR se ha generado por la crisis paraguaya de 1996, con el choque del presidente Wasmosy con el entonces General Oviedo, llevando a la amenaza de golpe militar. Este intento de golpe militar en Paraguay generó la reacción del MERCOSUR, llevando a la redacción de la Declaración Presidencial sobre Compromiso Democrático en el MERCOSUR, de 25 de junio de 1996, elaborada en la localidad de Potrero de Los Funes, Provincia de San Luis (Argentina). En esta última Declaración, los Estados decidieron que la democracia era un requisito previo para la continuación del proceso de integración.

Estas dos declaraciones demuestran que los Estados Partes del MERCOSUR percibirían que sería imposible la continuidad de un ambicioso proceso de integración (que aspira, en última instancia, la creación de un mercado común) sin que hubiera la construcción, en paralelo, de normas referentes al Estado de Derecho y la Democracia. Como se ha dicho, el respeto al Estado de Derecho y a la democracia imprime en los agentes económicos la fiabilidad necesaria para que se hagan las transacciones e inversiones esperadas.

Natural, entonces, que dos años más tarde, se haya celebrado el Protocolo de Ushuaia, que establece el mantenimiento de la democracia como razón para la continuidad de la existencia o el desarrollo del bloque, como veremos a continuación.

\subsection{Los Protocolos de Ushuaia I y II}

En 1998, fue firmado el Protocolo de Ushuaia sobre el Compromiso Democrático en el MERCOSUR ${ }^{24}$, a través del cual los cuatro miembros y los dos Estados asociados (Chile y Bolivia) reconocerían, en un tratado internacional, que la vigencia de las instituciones democráticas es una condición necesaria para el goce de los derechos del Estado miembro o asociado del proceso de integración del Cono Sur. Por lo tanto, toda ruptura del orden democrático se considera un obstáculo insalvable para el ingreso en el bloque o la continuación del proceso de integración.

En el caso de ruptura del orden democrático en un Estado Parte del Protocolo, los demás Estados Partes iniciarán consultas entre sí y con el Estado en crisis. Cuando las consultas resultaren infructuosas, los demás Estados Partes del Protocolo, en el ámbito específico de los acuerdos de integración vigentes entre ellos, deben decidir sobre la naturaleza y el alcance de las medidas de coerción - aspirando al retorno al régimen democrático - a aplicar, teniendo en cuenta la gravedad de la situación existente.

24 El Congreso brasileño aprobó el texto del Protocolo de Ushuaia sobre Compromiso Democrático en el MERCOSUR, Bolivia y Chile, a través del Decreto Legislativo no 452 , de 14 de noviembre de 2001. De acuerdo con el artículo 10 del Protocolo, esto entró en vigor, para Brasil, en 17 de enero de 2002. Sin embargo, el texto del Protocolo fue promulgado en Brasil por el Decreto ${ }^{\circ} 4.210$ solamente el 24 de abril de 2002 . 
El Protocolo, en su artículo $5^{\circ}$ establece que las medidas comprenderán desde la suspensión del derecho a participar en los distintos órganos de los respectivos procesos de integración a la suspensión de los derechos y obligaciones resultantes de estos procesos.

Las medidas previstas en el citado artículo $5^{\circ}$ deberán ser adoptadas por consenso por los Estados Partes de dicho Protocolo y comunicadas al Estado afectado, que no participará en el proceso decisorio pertinente. Estas medidas entrarán en vigor en la fecha en que se haga la comunicación respectiva. De acuerdo con el artículo $7^{\circ}$ del Protocolo, las medidas cesarán con el pleno restablecimiento del orden democrático.

A pesar de que haya sido tímido exigir el consenso para la toma de medidas de coerción, al menos el artículo $8^{\circ}$ establece que el Protocolo es parte integrante del Tratado de Asunción y de los respectivos Acuerdos de Integración celebrados entre el MERCOSUR, Bolivia y Chile.

En el mismo sentido, fue suscrita, en 1998, la Declaración Política del MERCOSUR, Bolivia y Chile como Zona de Paz, por la cual se decía que la paz constituye elemento esencial para el mantenimiento del proceso de integración regional. Los Estados signatarios de la citada Declaración se han comprometido a desarrollar mecanismos de consulta y cooperación en las áreas de defensa, seguridad, así como el desarme y el uso pacífico de la energía nuclear.

En 2004, el Régimen de Participación de los Estados Asociados del MERCOSUR, establecido por la decisión MERCOSUR/CMC No 18/04, determina (art. $2^{\circ}$ ) que la adhesión al Protocolo de Ushuaia y a la Declaración Presidencial sobre Compromiso Democrático en el MERCOSUR es una condición sine qua non para que un Estado venga a adquirir la condición de Estado Asociado al bloque, cláusula reiterada en 2013 (decisión CMC nº 11/13).

En diciembre de 2011, fue aprobada por el Consejo del Mercado Común la futura reforma del mecanismo democrático del MERCOSUR, con la adopción del Protocolo de Montevideo sobre Compromiso con la Democracia en el MERCOSUR (llamado por los propios escritores de Protocolo "Ushuaia II", para demostrar sus orígenes).

El nuevo Protocolo llena el vacío legal del anterior y establece, como ejemplos, algunas medidas que se pueden tomar para fomentar el retorno a la democracia, tales como: a) suspensión del derecho a participar en los distintos órganos de la estructura institucional del MERCOSUR; b) cierre de las fronteras; c) suspensión o limitación del comercio, el transporte aéreo y marítimo, las comunicaciones y el fortalecimiento de energía, servicios y suministros; $d$ ) suspensión de la parte afectada del goce de los derechos y beneficios emergentes de MERCOSUR; e) acciones de los otros Estados para fomentar la suspensión del Estado infractor en otras organizaciones internacionales, así como de los 
derechos derivados de otros acuerdos de cooperación; e) acciones de los Estados para apoyar los esfuerzos regionales e internacionales para el retorno a la democracia (por ejemplo, en las Naciones Unidas o en la Organización de los Estados Americanos) y $f$ ) adopción de sanciones políticas y diplomáticas adicionales.

El nuevo protocolo pretende evitar que "el inocente pague por lo culpable": Las medidas deben ser proporcionales a la gravedad de la situación existente y no deberán poner en riesgo el bienestar de la población y el goce efectivo de los derechos humanos y de las libertades fundamentales en el estado afectado.

De los miembros del MERCOSUR, solamente Venezuela ya lo ha ratificado. En Brasil, el proyecto de Decreto Legislativo $n^{\circ}$ 1290/2013 tramita, bajo régimen de urgencia, en el Congreso Nacional brasileño y fue aprobado por la Comisión de Constitución y Justicia de la Cámara de los Diputados, pero aún no ha sido votado en el pleno, habiendo sido retirado de la agenda el 01/06/2015.

Por lo tanto, el Protocolo de Ushuaia II no entró en vigor, pero puede servir como norte a la actuación de los Estados involucrados, a la vez que algunas de las medidas de coerción mencionadas anteriormente pueden ser adoptadas por los países del MERCOSUR, en el interior del bloque, o aún en sus propias acciones diplomáticas y en otras organizaciones internacionales.

\subsection{Protocolo de Asunción: la cláusula de derechos humanos}

El Protocolo de Asunción sobre Compromiso con la Promoción y Protección de los Derechos Humanos del MERCOSUR es más un paso hacia la consagración de la protección de los Derechos Humanos en el escenario de integración de MERCOSUR.

Aunque no contiene una "Carta de los Derechos Fundamentales", el Protocolo busca introducir -al menos en el preámbulo del tratado, como veremos- una "cláusula de Derechos Humanos del MERCOSUR". $\mathrm{Su}$ redacción es el resultado de la I Reunión de Altas Autoridades en Derechos Humanos y Cancillerías del MERCOSUR y Estados Asociados, foro creado en 2004, y fue prevista en la Declaración Presidencial de Puerto Iguazú de 8 de julio de 2004, en la que los presidentes de los Estados del MERCOSUR confirmarían el deseo de valorizar la promoción y garantía de los derechos humanos y las libertades fundamentales en el bloque.

Ya en los "considerandos" de la Decisión 17/05 del CMC que adoptó el Protocolo, se señaló que "es esencial asegurar la protección, promoción y garantía de los Derechos Humanos y de las libertades fundamentales de todas las personas" y que "el goce efectivo de los derechos fundamentales es una condición indispensable para la 
consolidación del proceso de integración”.

Sin embargo, es en el preámbulo que se encuentran las principales afirmaciones de los Estados Partes a favor de los derechos humanos en el bloque. En un primer momento, se señaló el seguimiento a los principios y normas contenidos (i) en la Declaración Americana de los Derechos y Deberes del Hombre, (ii) en la Convención Americana sobre Derechos Humanos y (iii) en otros instrumentos regionales de derechos humanos. Además, el preámbulo subrayó que la democracia, el desarrollo y el respeto de los derechos humanos y las libertades fundamentales son conceptos interdependientes que se refuerzan mutuamente, tal cual se expresó en la Declaración y en el Programa de Acción de la Conferencia Mundial de Derechos Humanos de 1993.

También se hizo referencia a las resoluciones de la Asamblea General y la Comisión de Derechos Humanos (ahora Consejo) de las Naciones Unidas, en las cuales se estableció que el respeto a los derechos humanos y las libertades fundamentales son elementos esenciales de la democracia.

Por otro lado, el preámbulo reconoció las características de universalidad, indivisibilidad, interdependencia e interrelación de todos los Derechos Humanos, sean derechos económicos, sociales, culturales, civiles o políticos.

A pesar de la fuerza retórica de los "considerandos" y del preámbulo, el contenido del Protocolo fue tímido. En resumen, el Protocolo creó un sistema de consultas similar al actualmente previsto en el Protocolo de Ushuaia para los casos de ruptura democrática, con previsión de adopción de medidas de reacción contra violaciones sistemáticas y graves de los derechos humanos en situaciones de "crisis institucional" o "vigencia de estados de excepción "(art. $\left.3^{\circ}\right)$.

Con esto, no están incluidos en el alcance del Protocolo los casos sistemáticos de violación de los derechos humanos sin crisis institucional o estado de excepción, como por ejemplo, se produce en el sistema penitenciario brasileño, en la miseria crónica de varias regiones brasileñas o paraguayas, en las favelas argentinas, etc.

Cuando dichas consultas resultan ineficaces, las demás Partes, por consenso, considerarán la naturaleza y el alcance de las medidas a ser implementadas, en vista de la gravedad de la situación existente. Dichas medidas abarcarán desde la suspensión del derecho a participar en este proceso de integración a la suspensión de los derechos y obligaciones que se derivan del (artículo $4^{\circ}$ ).

La falta de voluntad para aclarar el contenido de las medidas de coerción al Estado miembro violador de los derechos humanos se quedó evidente. Además, la regla del consenso (que prevalece en el MERCOSUR) también se adoptó aquí, lo que puede dificultar la adopción de cualquier medida más severa.

De cualquier modo, el Protocolo de Asunción es un paso 
importante en la construcción de la normativa del MERCOSUR, porque introduce el tema de la violación grave y sistemática de los Derechos Humanos como una preocupación adicional del bloque.

\section{LA OPCIÓN DELMERCOSUR POR EL MECANISMO HÍBRIDO: POLÍTICO CON REVISIÓN JUDICIAL}

Los mecanismos internacionales colectivos o institucionales de protección de derechos humanos son esenciales para la profundización de la defensa de los derechos humanos, pues evitan que los dispositivos presentes en los tratados de derechos humanos dependan exclusivamente de la interpretación e implementación a nivel local, que puede variar e incluso no existir.

También es posible clasificar estos mecanismos internacionales en cuanto a la naturaleza: hay el llamado mecanismo político y el mecanismo judiciario. El mecanismo político es el que constata la existencia de una violación de los derechos humanos a partir de una evaluación discrecional de carácter político de un Estado o de un colectivo de Estados. El mecanismo político puede ser unilateral o incluso colectivo, como se muestra en la apreciación de violaciones de derechos humanos en el Consejo de Seguridad, en el Mecanismo de Revisión Periódica del Consejo de Derechos Humanos o incluso en la Organización de los Estados Americanos.

Por su parte, el mecanismo judiciario es el que constata la existencia de una violación de los Derechos Humanos a partir de un procedimiento en el cual hay una amplia defensa y derecho de contradicción, así como jueces imparciales. Se puede llevar a cabo en los organismos internacionales y cuasi-judiciales (como los Comités de diversos tratados de derechos humanos - los "treaty bodies") o judiciales (los Tribunales Internacionales de Derechos Humanos, como las Cortes Europea e Interamericana de Derechos Humanos) $)^{25}$.

Sin embargo, el mecanismo político es criticado justamente por permitir una apreciación discrecional de los demás Estados sobre la existencia - o no - de violaciones de los derechos humanos en el Estado infractor, lo que puede generar selectividad y ambigüedad. También puede haber divergencias de apreciación y adopción de sanciones por parte de los diversos mecanismos políticos multilaterales. Especialmente cuando se trata de promover la democracia en el MERCOSUR, el caso del presidente Lugo, en 2012, se muestra bien la posibilidad de evaluaciones divergentes entre las organizaciones internacionales que poseen la llamada "cláusula democrática".

25 Sobre la clasificación de los mecanismos de protección de violaciones de derechos humanos, ver RAMOS, André de Carvalho. Processo Internacional de Direitos Humanos. 4a ed. São Paulo: Saraiva, 2015, en particular p. 36-38. 
El caso se refiere al procedimiento de impeachment y la destitución del Presidente Lugo en 2012 en Paraguay. Dada la rapidez del proceso de juicio político, con restricciones a la defensa legal y el contradictorio del presidente Lugo y con base en las disposiciones del primer Protocolo de Ushuaia, Paraguay fue suspendido, en decisión de fecha 29/06/2012, del derecho a participar de los órganos del MERCOSUR y sus deliberaciones hasta que fuera restablecido el orden democrático en el país. Sólo el 12 de julio de 2013, el MERCOSUR habría decidido retirar la sanción contra Paraguay, a partir del 15 de agosto de ese año, debido a la elección del nuevo presidente Horacio Cartes $^{26}$.

El caso Lugo muestra las diferencias generadas por la apreciación discrecional de la situación de los derechos humanos realizada desde el mecanismo internacional político: si bien MERCOSUR reaccionó partiendo de su constatación de ruptura del régimen democrático, la Organización de los Estados Americano (OEA), no lo hizo, a pesar de haber acompañado la crisis ${ }^{27}$. Para aumentar la complejidad del tema, la Unión Sudamericana de Naciones (Unasur) también consideró que hubo derrocamiento ilegítimo del Presidente electo y suspendió Paraguay de las actividades de esa organización internacional ${ }^{28}$.

Sin embargo, el impeachment del Presidente Lugo de Paraguay un hibridismo del modelo del MERCOSUR de promoción de la democracia, que, a pesar de ser esencialmente política, tiene un cierto tono "judiciario".

Este tono de mecanismo internacional judiciario se ve en la posibilidad de revisión jurídica, por el sistema de controversia del MERCOSUR, de las sanciones impuestas al Estado en el que hubo la presunta ruptura democrática. O sea, la discrecionalidad típica del mecanismo político puede ser contrariada por la fuerza del Derecho Internacional, gracias a la revisión jurídica de esas sanciones.

En el caso, Paraguay reaccionó a la decisión de suspensión tomada

\footnotetext{
26 Ver "Decisão sobre o fim da suspensão do Paraguai no Mercosul em aplicação do Protocolo de Ushuaia sobre compromisso democrático", de 12 de julio de 2013. Disponible en: <http:// www.MERCOSUR.int/show? contentid=4677\&channel=secretaria $>$ [último acceso en 25 de junio de 2015].

27 Sobre la postura distinta de la OEA mientras la crisis del impeachment del Presidente Lugo, véase MCCOY, Jennifer L. "Challenges for the Collective Defense of Democracy on the Tenth Anniversary of the Inter-American Democratic Charter" [en línea]. Latin American Policy.Vol 3, n 1, p. 33-57 [acceso 24 de junio de 2015]. Disponible en: <http://www. plataformademocratica.org/Publicacoes/22343.pdf>

28 La UNASUR también busca la promoción de la democracia en sus Estados miembros. El Protocolo Adicional al Tratado Constitutivo de la UNASUR sobre Compromiso con la Democracia", firmado en la IV Reunión del Consejo de Jefes de Estado de la UNASUR, realizada en Georgetown, Guiana, en 26 de noviembre de 2010 prevé mecanismo concreto para la protección, defesa y eventual restauración de la democracia. Tal cual el Protocolo de Ushuaia II, hay la previsión de adopción de medidas como el cierre de fronteras terrestres, limitación o suspensión del comercio, tránsito aéreo y marítimo, comunicaciones, provisión de energía e otros servicios, entre otras medidas en contra del Estado en lo cual hubo la ruptura democrática.
} 
por los demás Estados y los accionó ante el Tribunal Permanente de Revisión (TPR) del MERCOSUR, el 9 de julio de 2012. Paraguay solicitó que se declarasen inaplicables (i) la decisión que lo suspendió del bloque y (ii) la decisión de incorporación de Venezuela como miembro pleno del MERCOSUR. Paraguay sostuvo, respecto a la suspensión, la ocurrencia de vicios formales, como la falta de legitimidad de los Jefes de Estado para adoptaren las referidas decisiones y la no realización de consultas establecidas en el art. $4^{\circ}$ del Protocolo de Ushuaia, así como una cuestión de mérito, ponderando que no hubo ruptura del orden democrático del país con la deposición de su presidente.

En cuanto a la aplicación del Protocolo de Ushuaia, Argentina, Brasil y Uruguay se defendieron alegando que el TPR no podría juzgar el fondo debido a su incompetencia ratione materia por tratarse de un "litigio de carácter político" no alcanzado por el sistema de solución de controversias previsto en el Protocolo de Olivos (PO). En consecuencia, argumentarían los tres Estados demandados que el Protocolo de Olivos no es aplicable para resolver los conflictos derivados de la aplicación del Protocolo de Ushuaia (PU).

Los días 19, 20 y 21 de ese mismo mes, se reunieron los miembros titulares del TPR Carlos María Correa, José María Gamio, Roberto Ruíz Díaz Labrano, Welber Barral y Jorge Fontoura, que decidieron, de modo preliminar y unánimemente, por la competencia ratione materia de dicho Tribunal para apreciar la controversia sobre la legalidad de los procedimientos previstos en el Protocolo de Ushuaia, ya que el TPR podría decidir sobre controversias respecto de cualquier norma del MERCOSUR y no sólo sobre litigios comerciales ${ }^{29}$.

Sin embargo, por mayoría, el TPR señaló que el Protocolo de Olivos (PO) permite el acceso directo al TPR, sin la etapa anterior del tribunal ad hoc sólo cuando los Estados partes en la controversia acuerden expresamente someter el litigio directamente en única instancia al TPR (art. 23 del PO). Sin el consentimiento de los demás Estados Partes aún considerando que Paraguay no ha demostrado el intento de realizar negociaciones directas con los demás Estados (otra exigencia del sistema de controversias del MERCOSUR), el TPR no consideró posible conocer directamente el fondo de la demanda.

29 Ver el ítem 37 del informe: "Desde esta óptica, no se puede hablar de "falta de vocación" del sistema para solucionar controversias más allá de la esfera comercial. La legitimidad del sistema se fundamenta en la contribución a la estabilidad, en la medida en que avanza el proceso de integración, en sus diversas esferas. Esta legitimidad debe ser apreciada conforme al texto acordado en el PO por los Estados Parte, el cual no excluye a priori el análisis de cualquier tipo de controversia en el marco normativo del MERCOSUR". Tribunal Permanente de Revisão, "Laudo en el procedimiento excepcional de urgencia solicitado por la República del Paraguay en relación con la suspensión de su participación en los órganos del Mercado Común del Sur (MERCOSUR) y a la incorporación de Venezuela como miembro pleno", laudo $\mathrm{n}^{\circ}$ 01/2012, de 21 de julio de 2012. Disponible en: <http://www.mercosur.int/innovaportal/ file/440/1/laudo_01_2012_pt.pdf $>$, [último acceso en 24 de junio de 2015]. 
El informe $n^{\circ}$ 01/2012 del TPR indica, entonces, algunos pasos para el control de la acción de los Estados contra la ruptura democrática o incluso violaciones graves y sistemáticas de los derechos humanos en situaciones de crisis institucional: (i) exigencia de comprobación de negociaciones infructuosas; (ii) demanda de creación de tribunal arbitral ad hoc o (iii) consenso para que la demanda arbitral sea instaurada directamente en el TPR.

Por otro lado, en la hipótesis de los Estados del MERCOSUR por razones geopolíticas - ignoraren la ruptura democrática o graves y sistemáticas violaciones de derechos humanos, no se determina la revisión judicial de la omisión de los Estados en aplicar la cláusula democrática.

\section{CONCLUSIÓN: PERSPECTIVAS PARA LA DEFENSA DE LOS DERECHOS HUMANOS EN EL MERCOSUR COMO CONDICIÓN DE ADMISIÓN Y PERMANENCIA}

Al igual que ocurrió en la experiencia integracionista europea, el desarrollo del proceso de integración del MERCOSUR expone la importancia de una defensa endógena de los derechos humanos.

Las razones son variadas: 1) demostrar a las Cortes Supremas de los Estados la existencia de una protección equivalente de los derechos humanos, 2) vigilar el cumplimiento de la lista de los derechos ya establecido por tratados internacionales de derechos humanos (en especial la Convención Americana sobre Derechos Humanos, evitando la responsabilidad internacional de los Estados miembros ante la Corte de San José) y, finalmente, 3) proporcionar legitimidad interna y externa al proceso de integración.

Los pasos siguientes deben conducir a la consagración de una lista de derechos propia o importada de la Convención Americana sobre Derechos Humanos, así como de un sistema de solución de controversias abierto a la participación plena de los particulares. En ausencia de una Carta de los derechos fundamentales del MERCOSUR o de un tribunal permanente de acceso amplio, insta llenar esos vacíos con lo que existe actualmente tanto en el aspecto material (normas de derechos humanos) como procesal (mecanismo de protección).

Respecto a las normas de derechos humanos, se puede utilizar las normas establecidas por el derecho internacional de los derechos humanos (por ejemplo, la Convención Americana sobre Derechos Humanos), una vez que el Protocolo de Olivos establece expresamente que los árbitros del MERCOSUR pueden aplicar los principios del Derecho Internacional sobre el tema ${ }^{30}$. En cuanto a la parte procedimental

30 Ver el artigo 34: "Derecho aplicable. 1. Los Tribunales Arbitrales Ad Hoc y el Tribunal Permanente de Revisión decidirán la controversia en base al Tratado de Asunción, al Protocolo 
de protección, es posible utilizar el propio sistema actual de arbitraje ad hoc del MERCOSUR, a pesar de sus defectos, en particular, la falta de control de la omisión de los Estados en aplicar la cláusula democrática.

El control de la omisión de los Estados en invocar la cláusula democrática del MERCOSUR es más problemático. Hay, en este caso, necesidad de utilizar el sistema de la Convención Americana sobre Derechos Humanos en relación a los cuatro Estados del MERCOSUR que la han ratificado, así como reconocieran la competencia contenciosa obligatoria de la Corte Interamericana de Derechos Humanos (Argentina, Brasil, Paraguay y Uruguay). Por ejemplo, puede la Comisión Interamericana de Derechos Humanos, a partir de petición individual o interestatal, considerar que hubo ruptura democrática y llevar un caso a la Corte Interamericana de Derechos Humanos ${ }^{31}$.

En cuanto a Venezuela, que denunció la Convención Americana sobre Derechos Humanos en 2012, sigue existiendo la posibilidad de accionarse la competencia consultiva de la Corte Interamericana de Derechos Humanos, para que sea, por ejemplo, interpretada la compatibilidad del régimen de excepción o incluso de actos que llevaron a la ruptura democrática con la Convención Americana sobre Derechos Humanos. La competencia consultiva, aunque no vinculante, es importante instrumento de interpretación del real alcance y significado de las normas de derechos humanos aplicables en las Américas. La Corte Interamericana de Derechos Humanos (Corte IDH) puede interpretar cualquier instrumento de derechos humanos que incida sobre los Estados Americanos, siendo que Venezuela sigue como miembro de la Organización de los Estados Americanos. Si la opinión consultiva de la Corte IDH indica ruptura del régimen democrático, los Estados del MERCOSUR pueden ser sensibilizados para hacer cumplir la cláusula democrática.

Dichas soluciones, aunque imperfectas como hemos visto, se deben utilizar hasta que se alcance una amplia reforma de la temática en el MERCOSUR, dada la importancia de la promoción del régimen democrático y de la protección de los derechos humanos para la continuación y profundización del proceso de integración.

\section{REFERENCIAS BIBLIOGRÁFICAS}

ALMEIDA, Paulo Roberto de. O estudo das relações internacionais do Brasil. São Paulo: Unimarco Editorial, 1999.

de Ouro Preto, a los protocolos y acuerdos celebrados en el marco del Tratado de Asunción, a las Decisiones del Consejo del Mercado Común, a las Resoluciones del Grupo Mercado Común y a las Directivas de la Comisión de Comercio del MERCOSUR así como a los principios y disposiciones de Derecho Internacional aplicables a la materia."

31 Ver más sobre el sistema interamericano de derechos humanos en RAMOS, André de Carvalho. Processo Internacional de Direitos Humanos. 4a ed, São Paulo: Saraiva, 2015. 
BAPTISTA, Luiz Olavo. O Mercosul - suas instituições e ordenamento jurídico. São Paulo: Ltr, 1998.

CASELLA, Paulo Borba. Mercosul: exigências e perspectivas. Integração e Consolidação de espaço econômico. São Paulo: Ltr, 1996.

DREYZIN DE KLOR, Adriana e ARROYO, Diego P. Fernández. "O Brasil diante da institucionalização e ao Direito do Mercosul”. En: MENEZES, Wagner (ed). O Direito Internacional e o Direito Brasileiro. Homenagem a José Francisco Rezek. Ijuí: Editora Unijuí, 2004. p. 318-353.

MCCOY, Jennifer L. "Challenges for the Collective Defense ofDemocracy, on the Tenth Anniversary of the Inter-American Democratic Charter" [en línea]. Latin American Policy. Vol 3, n 1, p. 33-57 [acceso 24 de junio de 2015]. Disponible en: <http://www.plataformademocratica. org/Publicacoes/22343.pdf >.

RAMOS, André de Carvalho. Direitos Humanos na Integração Econômica. Análise comparativa da proteção de direitos humanos e conflitos jurisdicionais na União Europeia e Mercosul. Rio de Janeiro: Renovar, 2008.

RAMOS, André de Carvalho. Processo Internacional de Direitos Humanos. 4a ed. São Paulo: Saraiva, 2015.

RAMOS, André de Carvalho. Teoria Geral dos Direitos Humanos na Ordem Internacional. 5a ed. São Paulo: Saraiva, 2015.

SABÓIA, Gilberto Vergne. "União Européia, Mercosul e a proteção dos direitos humanos". En: PIOVESAN, Flávia (ed). Direitos Humanos, Globalização Econômica e Integração Regional. São Paulo: Ed. Max Limonad,'2002. p. 163-170.

SEITENFUS, Ricardo. Manual das Organizações internacionais. 2a ed. Porto Alegre: Livraria do Advogado, 2000.

VILLALÓN, Pedro Cruz. "Formación y evolución de los derechos fundamentales". Revista Española de Derecho Constitucional. 1989, vol 25. p. 35 y s. 